\title{
Pathologic Stage IIB Merkel Cell Carcinoma AJCC v8
}

National Cancer Institute

\section{Source}

National Cancer Institute. Pathologic Stage IIB Merkel Cell Carcinoma A/CC v8. NCI

Thesaurus. Code C136885.

Stage IIB includes: T4, N0, M0. T4: Primary tumor invades fascia, muscle, cartilage, or bone. N0: No regional lymph node metastasis detected on pathologic examination. M0: No distant metastasis detected on clinical and/or radiologic examination. (AJCC 8th ed.) 